\title{
Conflitos políticos e articulações sociais: a história dos limites entre São Paulo e Minas Gerais na formação do território nordeste paulista - 1720 a 1935
}

PICCINATO JUNIOR, Dirceu

SALGADO, Ivone

Resumo

O desenvolvimento histórico de um determinado contexto se faz sobre e com o espaço terrestre, e, dessa forma, toda formação social também é territorial, pois, necessariamente, o social se espacializa. Neste sentido, o objetivo deste trabalho é analisar e discutir os conflitos políticos acerca dos limites territoriais entre São Paulo e Minas Gerais e as articulações sociais dos entrantes mineiros, conferindo destaque ao significado de território e aos processos de formação, ocupação e transformação do que é hoje o território ocupado do nordeste paulista. A questão acerca das disputas territoriais entre paulistas e mineiros começou no ano de 1720, quando ocorreu a primeira demarcação oficial. A partir dessa data, houve inúmeras e sucessivas tentativas de encerrar essas disputas, situação que só foi resolvida em 1935, quando foram efetivamente definidos e aceitos entre as partes os limites respectivos. Paralelamente aos conflitos políticos, a migração de mineiros para o nordeste paulista marcou a conformação social desse espaço físico. A história da formação desse território revela, portanto, uma sociedade específica em um espaço determinado, num intercâmbio contínuo que possibilitou a humanização dessa área, materializando a sociabilidade numa paisagem e numa estrutura territorial.

Palavras-chave: Disputas e Formação. São Paulo e Minas Gerais. Conflitos Políticos. Articulações Sociais. Território Nordeste Paulista.

\begin{abstract}
:
The historical development of a given context takes place over and with terrestrial space, hence every social formation is also territorial because the social element becomes spatialized. Therefore, the aim of this paper is to analyze and discuss political conflicts caused by territorial boundaries between São Paulo and Minas Gerais, as well as the social articulations of incoming people from Minas Gerais, giving particular emphasis to the meanings of territory and of training, occupation, and transformation processes of what is now the occupied territory of northeastern São Paulo. Territorial disputes between paulistas and mineiros began in 1720, when the first official demarcation took place. Since then, numerous attempts have been made to bring an end to these disputes, a situation only resolved in 1935, when limits were effectively defined and agreed by the parties. Parallel to these political conflicts, the migration of mineiros to northeastern São Paulo established the social formation of that physical space. This territory's formation history reveals, therefore, a particular society at a particular place, in a continuous exchange that enabled the humanization of the area, materializing sociability within a landscape and a territorial structure.
\end{abstract}

Keywords: Disputes and Formation. São Paulo and Minas Gerais. Political Conflicts. Social Articulations. Territory of Northeastern São Paulo. 


\section{Introdução}

O território é, antes de qualquer ideia, o resultado de relações de poder, o que significa que não há um território sem que, antes, ocorra uma trama de relações sociais. Em suma, "o território é um produto socioespacial de relações sociais que são econômicas, políticas e culturais e de ligações de redes internas e externas" (SAQUET, 2013, p. 81).

Um território pode ser formado por intermédio de uma construção militar (como resultado de conquista), como construção política (área de exercício de domínio), como construção econômica (atividades produtivas), como construção jurídica (legitimidade do espaço) e, por fim, como construção ideológica (identidade social alicerçada em uma base espacial). "A constituição de um território é, assim, um processo cumulativo, a cada momento um resultado e uma possibilidade - um contínuo em movimento" (MORAES, 2005, p. 45).

O significado desse termo também pode estar associado à natureza e sociedade; economia, política e cultura; ideia e matéria; identidades e formas de representações; apropriação, dominação e controle; descontinuidades; conexão e redes; domínio e subordinação; degradação e proteção do meio ambiente; terra, formas espaciais e relações de poder; diversidade e unidade. Assim, "cada combinação específica de cada relação espaço-tempo é produto, acompanha e condiciona os fenômenos e processos territoriais" (SAQUET, 2013, p. 24).

Como o objetivo deste trabalho é discutir a ocupação, formação e transformação do território nordeste paulista, segundo os conflitos históricos entre São Paulo e Minas Gerais, o significado de território que melhor define a escala socioespacial deste estudo é o conceito de território compreendido como fato social e político. Antonio Carlos Robert Moraes (2013, p. 101) acrescenta que o território não se restringe apenas a um lugar de ação pragmática, mas num espaço de trocas materiais e espirituais e da vida. Assim, assumimos para este momento a ideia de território como produto das relações de poder, dos conflitos de interesses e das articulações sociais.

\section{Disputas políticas e territoriais entre paulistas e mineiros}

Em 23 de novembro de 1709, D. João V, rei de Portugal, determinou a criação da Capitania de São Paulo, que foi desmembrada da Capitania do Rio de Janeiro. A Capitania paulista compreendia terras dos atuais estados de Mato Grosso, Mato Grosso do Sul, Rondônia, Goiás, Tocantins, Minas Gerais, São Paulo, Paraná, Santa Catarina e Rio Grande do Sul. Em 1714, teve início o desbravamento da região de São João d'El Rei em busca de riquezas minerais, que logo foram encontradas em abundância.

Com o intuito de obter maior controle sobre as terras ricas em ouro e pedras preciosas, a Coroa portuguesa determinou, em 1720, a criação da Capitania das Minas de Ouro, desmembrada da Capitania de São Paulo (Figura 1). Com a criação da nova Capitania pelo alvará régio, fez-se necessária a primeira demarcação oficial entre terras paulistas e mineiras:

\footnotetext{
Hei por bem que na Capitania de São Paulo se crie hum novo governo e haja nelle hum Governador com a mesma jurisdicção, prerrogativas e soldo de oito mil cruzados cada anno, pagos em moeda e não em oitavos de ouro, e lhe determino por limites no sertão, pela parte que confina com o Governo de Minas, os mesmos confins que tem a comarca e ouvidoria de São Paulo com a comarca e ouvidoria do Rio das Mortes e pela parte marinha quero que the pertença o porto de Santos, e os mais daquella costa, que Ihe ficão ao Sul, aggregando-se-lhe as Villas de Paraty, de Ubatuba e da llha de São Sebastião que desannexo do Governo do Rio de Janeiro. (Apud CINTRA, 1935, p. 8).
}

Figura 1: Indicação da área de conflito no Mappa da capitania de S. Paulo, e seu sertão em que devem os descobertos, que Ihe forão tomados para Minas Geraes..., século XVIII, elaborado por Francisco Tosi Columbina. A mancha em cinza indica as zonas de litígio.

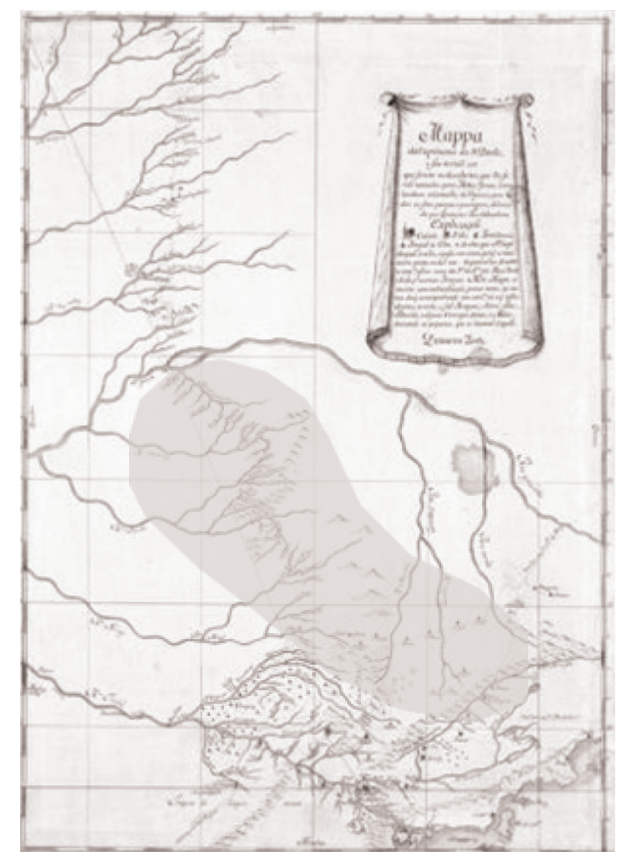

Fonte: Fundação Biblioteca Nacional. 
Nestes tempos do século XVIII, o que valorizava os novos territórios, conferindo motivo à sua ocupação e povoamento, eram os descobertos de ouro (DOCUMENTOS INTERESSANTES V. XI, 1896, p. 14). Essa assertiva, possivelmente, foi a justificativa encontrada para que a Capitania das Minas de Ouro mudasse "furtivamente o marco do morro do Caxambú para a serra da Mantiqueira" (CINTRA, 1935, p. 9), como infere a representação que o governador de São Paulo, Antonio da Silva Caldeira, nomeado em 1727, enviou ao rei de Portugal, na qual solicitava que as divisas fossem restabelecidas ${ }^{1}$.

Uma vez consumada a usurpação de parte do território de São Paulo, foi anulada a demarcação dos limites de 1720. No ano de 1731, D. João $\mathrm{V}$, por meio da Provisão Régia de 23 de fevereiro e a pedido do governador paulista, determinou novas divisas:

\section{Fui servido por resolução de 20 deste mez e anno em consulta do Meu Conselho Ultramarino ordenar que o governador dessa Capitania (S. Paulo) se alargue para os montes (Serra da Bôa Vista) que ficam entre a Villa de Guaratinguetá e Rio das Mortes; pelo que ordeno ao governador das Minas que convosco ajuste os limites, que por esta devem ter hum e outro governo, e me dareis conta para o approvar. (Apud CINTRA, 1935, p. 10, grifo nosso).}

Essa segunda demarcação, prevista na Provisão Régia de 23 de fevereiro de 1731, suscitou dúvidas, pelo fato de ter ficado incompleta em decorrência de o governador mineiro não cumprir o que determinava a Coroa. Além desse fato, a descrição da Provisão Régia de 1731 deixou a responsabilidade de legitimar as divisas em comum acordo para ambos os governadores, o que, de fato, não aconteceria, pois estava em disputa o interesse por futuras áreas auríferas.

O conde de Bobadella, Gomes Freire de Andrade, então governador da Capitania do Rio de Janeiro, preocupado com a situação, enviou um ofício ao Rei, em 1747, para que uma nova demarcação fosse estabelecida entre a

1. Segundo Cintra (1935, p. 9), era extremamente inconveniente tomar como referência de limites entre as duas Capitanias apenas um marco de pedra, em um determinado morro de uma região sertaneja. Pouco depois da emancipação das Minas, começaram os conflitos. Nesse momento, quando a comarca de São João d'El Rei, também conhecida como Rio das Mortes, mudou sem maiores explicações o marco, o governador de São Paulo, na época Antonio da Silva Caldeira, nomeado em 1727 enviou uma carta ao Rei de Portugal sobre a mudança e que de pronto fosse estabelecido o morro do Caxambú ou Bôa Vista como marco, que poderá ser observado na Figura 2.
Capitania de São Paulo e a Capitania das Minas do Ouro. Em 30 de abril de 1747 foi emitida a Provisão Régia que determinava a serra da Mantiqueira como limite entre as duas Capitanias.

Entretanto, paralelamente à questão da divisão civil entre as duas Capitanias, havia ocorrido a divisão eclesiástica entre dois bispados, o de São Paulo e o de Mariana, "a bulla creando em 1745 os bispados de São Paulo, Marianna e Goyaz marcou os limites dos dois primeiros em termos que admittiam diversas interpretações" (DOCUMENTOS INTERESSANTES (v. XI, 1896, p. 38).

A conformação territorial adotada por Portugal tinha como condição gerar rendimentos; assim, tributações, impostos e outros tipos de encargos foram promulgados. Como alternativa para pagar os impostos reais, as capitanias buscaram na ampliação de suas fronteiras novas áreas contribuintes. Segundo Beatriz P. S. Bueno (2009, p. 270), em seu estudo sobre a formação da Capitania de São Paulo (1532-1822), na lógica do processo de colonização, a mudança por áreas de interesse e a importância quanto ao controle metropolitano em determinada região condicionavam a redefinição das outras regiões.

Quando da publicação da terceira demarcação (ano de 1747), já se davam notícias de novas descobertas em terras da Capitania de São Paulo. Os mineiros encontravam-se intimidados pelos paulistas em razão do conflito anterior, assim, ao contrário da violência, Minas Gerais movimentou seu abundante ouro com interesse nas novas descobertas. O resultado foi infeliz: o aniquilamento da Capitania de São Paulo, que foi anexada à Capitania do Rio de Janeiro em 1748. Para Bueno (2009, p. 278), a partir de então, a Capitania de São Paulo deixou de ter um governo autônomo, ficando como simples comarca. "Escapando aos olhos fixos de Portugal, desenvolveu-se ao sabor das circunstâncias".

A Carta Régia de 9 de maio de 1748 decretou que D. Luís de Mascarenhas, defensor de São Paulo, deveria voltar para Lisboa. Goiás e Mato Grosso foram desmembrados do território paulista. Nessa mesma Carta, o Rei de Portugal concedeu plenos poderes ao governador da Capitania do Rio de Janeiro para que demarcasse novas divisas "entre S. Paulo e Minas, pelo Rio Grande e pelo rio Sapucahy, ou por onde the parecesse" (CINTRA, 1935, p. 14).

O conde Gomes Freire governou as Capitanias de São Paulo, Minas Gerais e Rio de Janeiro até 
sua morte, em 1763. Para substituí-lo, o governo de Portugal nomeou o conde da Cunha como vice-rei do Brasil e governador especial do Rio e de São Paulo. Para a administração da Capitania de Minas foi nomeado Luís Diogo Lobo da Silva.

No ano seguinte (1764), a metrópole taxou o imposto de cem arrobas de ouro por ano. Os habitantes das minas se mostraram descontentes com o tributo; em setembro desse mesmo ano, Luís Diogo saiu para "dar um giro pelos confins da mesma comarca (São João d'El Rei)" (apud CINTRA, 1935, p. 18) e, nesse "giro", avançou um pouco mais sobre as terras auríferas paulistas.

O conde da Cunha, preocupado com a situação de São Paulo, enviou uma representação à Coroa sugerindo o restabelecimento da Capitania paulista. Em Carta Régia de 4 de fevereiro de 1765, a Coroa respondeu à representação do conde com parecer positivo para o restabelecimento de São Paulo e nomeando D. Luiz Antônio de Souza Botelho Mourão, o Morgado de Mateus, como governador e capitão-general da mesma Capitania.

Segundo Heloísa L. Bellotto (1979, p. 45), a restituição da autonomia da Capitania não tinha a ver apenas com uma necessidade geral, geopolítica e administrativa, mas também com uma necessidade econômica, o renascimento da agricultura. A pesquisadora Maria Fernanda Derntl (2013, p. 74-75), em trabalho recente, acrescenta que a Coroa Portuguesa impôs também uma nova agenda para a Capitania de São Paulo sob o governo de Mateus, a de povoar com sentido de reorganizar a distribuição espacial da população. "Povoar aproximava-se da noção de urbanizar".

No ano de 1765, em razão das disputas entre mineiros e paulistas acerca dos limites das Capitanias, o conde da Cunha organizou uma "Junta" com homens ilustrados daquele tempo para que pudessem fazer as demarcações, seguindo as formalidades legais da época. Essa "Junta" ficou conhecida como "Assento da Junta do Rio de Janeiro" e estabeleceu novos limites conforme o mapa elaborado pelo Morgado de Mateus em 1766 (Figura 2).

A legenda deste mapa, no alto, do lado direito, apresenta alguns códigos e refere-se a alguns pontos que foram utilizados como marcos divisórios. A delimitação das divisas se inicia no primeiro quadrante depois da linha do Trópico de Capricórnio, lado direito. Tendo como ponto de partida o rio Grande (A1), o traçado percorre o morro do Caxambu (A2), morro pertencente às
Figura 2: Interpretação da divisa entre Minas e São Paulo na Carta Chorografica da Capitania de São Paulo..., elaborada pelo Morgado de Mateus. A linha cinza escura grossa e os códigos (A1, A2, A3, A4, A5, A6 e A7) definem as divisas entre Minas Gerais e São Paulo. A linha cinza clara grossa define o caminho de Goiás.

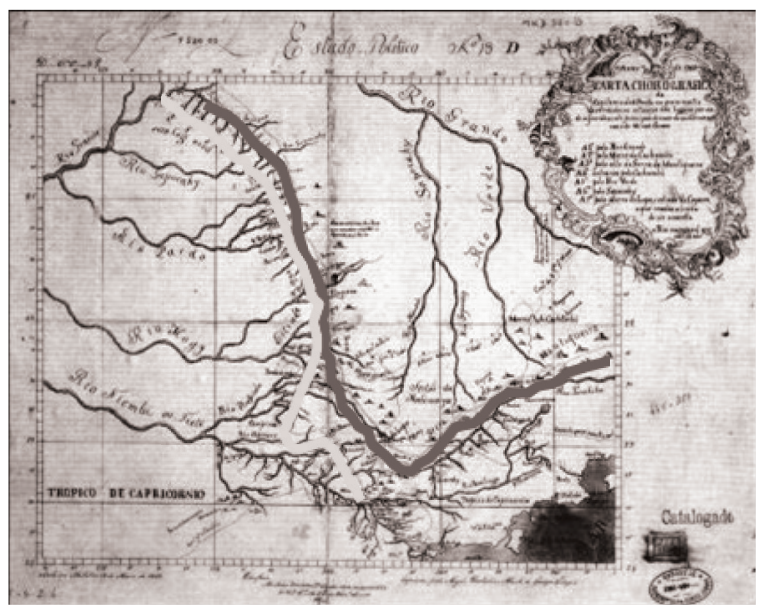

Fonte: Novo Milênio. Disponível em < http://www.novomilenio. inf.br/santos/lendasnm.htm>. Acesso em: 12 jul. 2014.

Gerais; em seguida a linha transpassa a serra da Mantiqueira (A3), em seguida passa novamente pelo morro do Caxambu (A4), depois segue pelo rio Verde (A5), para logo depois alcançar o rio Sapucaí (A6) mineiro, por fim chega ao morro do Lopo (A7) e segue seu trajeto pela estrada de Goiás.

No Brasil Império, entre os anos de 1827 e 1879, tanto a Província de São Paulo como a Província de Minas Gerais emitiram uma série de representações, pareceres e entendimentos que não avançaram. Segundo Maria Fernanda Derntl (2013, p. 131), a Coroa, de certo modo, sempre favoreceu discretamente os mineiros, já que o alargamento de seus territórios lhe renderia maiores vantagens fiscais.

Com a instauração da República no Brasil (1889), novamente mineiros e paulistas tentaram chegar a um acordo acerca das divisas de seus estados. Convênios, acordos, projetos, decretos, relatórios, entre outros, foram elaborados, porém nenhum deles proporcionou uma conciliação de comum acordo. Foi somente em 25 de maio de 1935 que o Decreto Constitucional do Governador de São Paulo, Armando de Salles Oliveira, conseguiu a fixação de uma linha conciliatória "para a solução definitiva da questão de limites" (CINTRA, 1935, p. 104).

Colocava-se, assim, fim a um conflito que perdurou por mais de dois séculos. Paralelamente a esses acontecimentos, o nordeste do estado de São Paulo, com os entrantes mineiros, foi perdendo gradualmente o status de sertão para formar um território, não mais entendido como 
elemento natural ou artificial, mas como produto das relações sociais e políticas a partir das quais, ao longo desse período de conflito, uma rede de cidades se formou.

\section{Mineiros em terras paulistas: a formação territorial do nordeste de São Paulo}

O movimento migratório de mineiros em direção às terras paulistas, especialmente ao nordeste, começou de maneira tímida e pouco expressiva, a partir das últimas décadas do século XVIII, mas, já nos primeiros anos do século XIX, houve uma intensificação desse movimento.

Segundo Cláudia Damasceno Fonseca (2011, p. 34), essa disseminação de mineiros em direção às terras próximas e incultas não pode ser justificada exclusivamente pela exaustão da economia mineira que começou a partir do século XVIII. "Durante este período, o povoamento dissemina-se pelas regiões periféricas, afastadas dos principais centros de poder, e deve-se menos à mineração que às atividades agropecuárias e comerciais".

Era fato o descontentamento geral dos habitantes da Capitania de Minas Gerais com o pagamento do Imposto Real (lei de dezembro de 1750). Se moradores e governantes não conseguissem atingir tal cifra, era cobrada deles a "derrama"; uma vez não atingidas as arrobas de ouro, caberia a todos da Capitania mineira se juntarem e doarem o que tinham em ouro e pedras preciosas até atingir as cem arrobas estabelecidas.

Outro fator a ser analisado é a Lei da Polícia de 25 de junho de 1765. Para Heloísa L. Bellotto (1979, p. 94), essa lei regulava a movimentação de cidadãos. De certa maneira a lei de 1765 buscava controlar a saída e o regresso de paulistas. O Morgado de Mateus, com o objetivo de restabelecer a Capitania de São Paulo, adotou uma política de controle e povoamento. Essa vigilância por parte das autoridades paulistas foi mencionada pelo Governador das Minas, Bernardo José de Lorena², em carta de 1765:

\footnotetext{
Esta Capitania [Minas Gerais], pela sua vastíssima extensão e igual Povoação quase circular, não permitte darem-se Despachos para sahirem della os seus habitantes como na de S. Paulo se pratica, motivo porque não posso alterar o que sempre se observou, por evitar infinito incommodo a estes Povos. (Apud CINTRA, 1935, p. 39)
}

Segundo Lucila R. Brioschi (1995, p. 39), desde fins do século XVIII os criadores mineiros começaram a descer a Serra da Mantiqueira, procurando se estabelecer em São Paulo, precisamente nas terras da então freguesia de Franca, momento em que existia uma incipiente rede urbana. Esses entrantes das Gerais "dedicavam-se sobretudo à criação de gado e à formação das tradicionais roças de milho, feijão, mandioca e outros gêneros usados no seu sustento e ração complementar para as criações".

Aparentemente, os primeiros mineiros que se aventuraram pelo nordeste paulista não vieram de maneira despreparada. Havia uma sistemática mais ou menos regular. Antes de migrar, a maioria dos entrantes buscava informações com familiares que ainda estavam nas Gerais sobre os parentes que já haviam se estabelecido no então Sertão do Rio Pardo, território que pertencia à vila de Mogi Mirim, e sobre as localidades em que se encontrariam terras boas e incultas. "Somente após a instalação das primeiras benfeitorias e colhidos os primeiros frutos, o restante da família passava para a nova moradia" (BACELLAR; BRIOSCHI, 1999, p. 66).

Em fins do século XVIII, o interesse por parte dos mineiros nessa região era modesto. No início do século XIX, esses números sofrem alterações, em razão da formação da Freguesia de Franca em 1804 (PICCINATO JR., 2012, p. 53). No ano de 1804, o número de mineiros nessas terras representava $24,7 \%$, de outras origens $4,6 \%$, para um total de terras desocupadas de $71,7 \%$. Em 1824, quando já haviam sido fundadas as Freguesias de Casa Branca e Batatais, respectivamente nos anos de 1814 e 1815, o número de mineiros passou para $75 \%$, de outras origens caiu para $3 \%$ e o total de terras ainda incultas representava 22\% (CHIACHIRI FILHO, 1986, p.141).

A naturalidade dos migrantes das Gerais entre os anos de 1804 e 1824 era, em sua maior parte, das comarcas centrais das Minas Gerais. Da Comarca do Rio das Mortes migraram $310 \mathrm{mi}-$ neiros, representando um total de 40,61\%; da Comarca do Rio das Velhas, 213, equivalendo a 27,90\%; da Comarca de Ouro Preto, 83, ou seja, $10,87 \%$ do total; da Comarca de Paracatu, 81 mineiros, representando 10,87\%; e da Comarca

2. Bernardo José de Lorena governou a Capitania de São Paulo entre os anos de 1788 e 1797. Em 1797, logo depois de deixar o cargo de governador de São Paulo, assumiu o cargo de Governador da Capitania de Minas Gerais, que exerceu até 1805. 
Figura 3: Interpretação nossa na Carta topographica e administrativa da província de Minas Geraes, 1849, de Visconde de Villiers de L'lle Adam. Destacamos nesta Carta as Cormarcas de origem dos entrantes mineiros no nordeste de São Paulo.

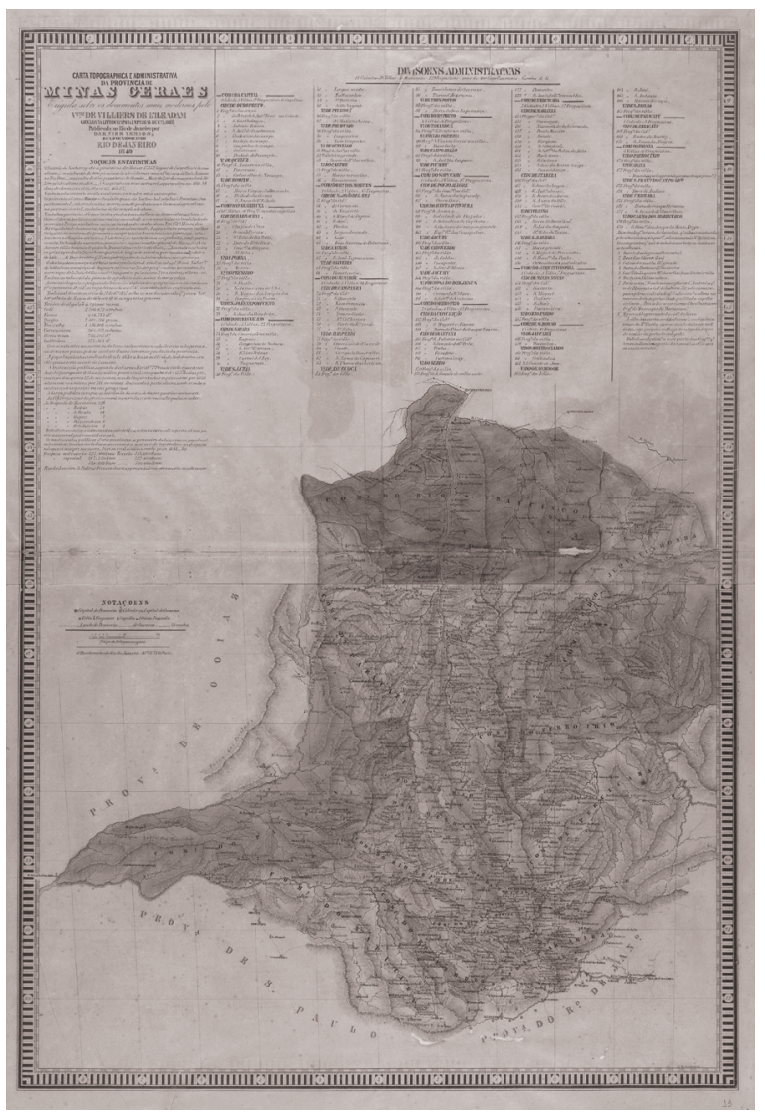

Fonte: Fundação Biblioteca Nacional.

do Serro $\mathrm{Frio}^{3}$, apenas um entrante foi registrado, porcentagem de $0,13 \%$. Populações de outras regiões do Brasil (Goiás, Rio de Janeiro e São Paulo) e de Portugal, juntas, representaram apenas $9,42 \%{ }^{4}$ (Figura 3 ).

Outro aspecto interessante refere-se à estrutura familiar. O número de famílias formadas por "casal+filhos" destacava-se em relação às demais estruturas, como "casal+agregados", "casal só", entre outros. O número de famílias formadas por casal mais os filhos era de 24 no ano de 1801; no ano de 1817, os números chegam a 169 famílias e, em 1825, já se somavam 292 famílias (BRIOSCHI, 1995, p. 169). A família nuclear foi a responsável pelas articulações sociais que resultaram na formação territorial do nordeste do estado de São Paulo.

3. Nos livros de casamentos da Igreja Matriz de Franca encontramos referência à Comarca do Serro Frio, na Carta topografhica.... Essa Comarca está escrita como Comarca do Ferro Frio.

4. As porcentagens referem-se à quantidade de noivos originários dos núcleos urbanos das Comarcas de Minas Gerais e de outras regiões do Brasil. Fonte: Livros de casamentos da Igreja Matriz de Franca.
São Paulo buscou, por meio da política de povoar do Morgado de Mateus, respaldo para manter o território nordeste paulista sob sua administração, pois Minas Gerais, por intermédio da Vila de Jacuí, tentava anexar essa região à sua Capitania. "Durante a administração do Conde de Palma ${ }^{5}$ a questão local de maior importância foi a dos limites entre Franca e Jacuhy, que já antes tinham reclamado simultaneamente a passagem da categoria de freguezia para a de Villa" (DOCUMENTOS INTERESSANTES v. XI, 1896, p. 59). Franca foi fundada como Freguesia da Vila de Mogi Mirim em 1804, durante o governo de Antônio José da Franca e Horta (1802-1811). Para a formação territorial da nova freguesia, o governo da Capitania de São Paulo destinou o território entre o rio Mogi Guaçu e o rio Grande, terras estas desmembradas da Vila de Mogi Mirim (Figura 4).

Figura 4: Em destaque, as terras que foram desmembradas da vila de Mogi Mirim para formar a Freguesia de Franca em 1805. Interpretação feita sobre o Mapa da Província de São Paulo, 1879, de Claudio Lomellino de Carvalho.

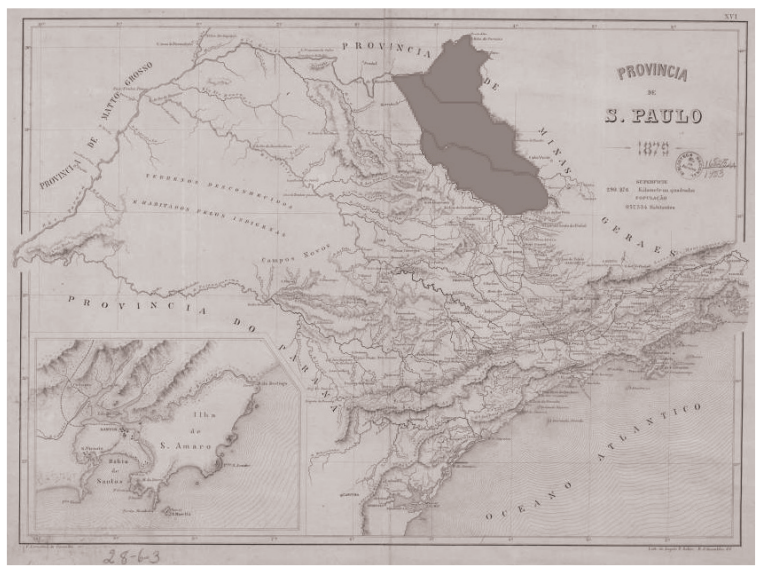

Fonte: Fundação Biblioteca Nacional (adaptado pelos autores).

Em 1814, a então Freguesia de Jacuí, pertencente à Vila de Campanha-MG, foi elevada à condição de Vila. Sentindo-se ainda mais fortalecida, já que Franca se manteve como Freguesia, Jacuí continuou com as investidas sobre as terras da região de Franca. Preocupados com a situação, os administradores civis e eclesiásticos paulistas atenderam aos pedidos para a criação de mais duas freguesias. Em 1814, foi fundada a Freguesia de Casa Branca e, em 1815, a de Batatais, ambas subordinadas à Vila de Mogi Mirim, e, novamente, o território do nordeste paulista passou por uma reconfiguração (Figura 5).

5. O conde de Palma, Francisco de Assis Mascarenhas, foi governador de Goiás entre os anos de 1804 e 1809. Depois se tornou governador da Capitania das Minas Gerais durante os anos de 1810 a 1814 e, em seguida, passou a governar a Capitania de São Paulo, entre os anos de 1814 e 1819, assumindo em seguida a Capitania da Bahia. 
Figura 5: Em destaque a Freguesia de Franca (1), Freguesia de Batatais (2) e a Freguesia de Casa Branca (3). Interpretação feita sobre o Mapa da Província de São Paulo, 1879, de Claudio Lomellino de Carvalho

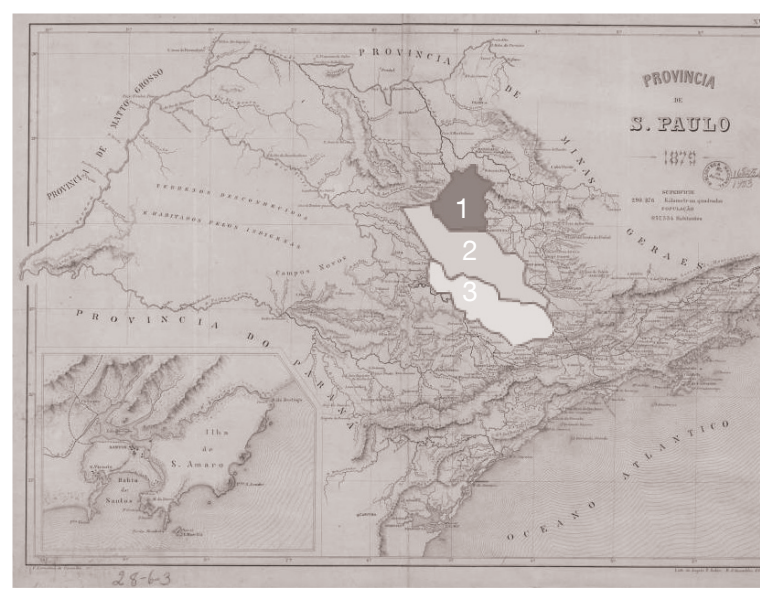

Fonte: Biblioteca Nacional
Mesmo com a formação das três freguesias, a Vila de Jacuí ainda alimentava o desejo de domínio dessas terras. Em 1821, a freguesia de Franca foi elevada ao status de vila, consequentemente, ela passou a ter o direito de se autogerir, de possuir uma câmara e a jurisdição de um território e terras para a renda. Dessa forma, as Freguesias de Batatais e Casa Branca passaram para a responsabilidade da Câmara de Franca.

Os desmembramentos territoriais na área em litígio entre paulistas e mineiros conformaram historicamente uma rede urbana complexa (Tabela 1).

\section{Conclusão}

Este trabalho buscou esclarecer que território não significa necessariamente a circunscrição de um espaço territorial, pois que se fundamenta na atuação de outros elementos, de outras condicionantes. As análises e discussões apontaram que um território é o conteúdo de suas relações. É o que acontece em sua unidade

Tabela 1: Desmembramento territorial e urbano do nordeste paulista.

\begin{tabular}{|c|c|c|}
\hline Franca (1804) & Casa Branca (1814) & Batatais (1815) \\
\hline Ituverava (1847) & Caconde (1841) & Cajuru (1850) \\
\hline Igarapava (1851) & São Simão (1842) & Ipuã (1859) \\
\hline Rifaina (1873) & Mococa (1856) & Santo Antônio da Alegria (1866) \\
\hline Patrocínio Paulista (1874) & Divinolândia (1865) & Morro Agudo (1872) \\
\hline Jeriquara (1885) & Santa Rita do Passa Quatro (1870) & Nuporanga (1873) \\
\hline Buritizal (1897) & Ribeirão Preto (1870) & Jardinópolis (1892) \\
\hline São José da Bela Vista (1897) & São José do Rio Pardo (1874) & Cássia dos Coqueiros (1899) \\
\hline Itirapuã (1900) & Santa Cruz das Palmeiras (1881) & Brodósqui (1902) \\
\hline Pedregulho (1902) & Serra Azul (1885) & São Joaquim da Barra (1902) \\
\hline Cristais Paulista (1910) & Tambaú (1892) & Sales Oliveira (1906) \\
\hline Ribeirão Corrente (1910) & Santa Rosa do Viterbo (1896) & Guaíra (1908) \\
\hline Restinga (1911) & São Sebastião da Gama (1896) & Orlândia (1909) \\
\hline Guará (1914) & Itabi (1898) & \\
\hline Miguelópolis (1927) & São Sebastião da Gama (1898) & \\
\hline \multirow[t]{4}{*}{ Aramina (1934) } & Tapiratiba (1906) & \\
\hline & Pontal (1907) & \\
\hline & Serrana (1912) & \\
\hline & Padrópolis (1916) & \\
\hline
\end{tabular}

Fonte: SÃO PAULO (Estado). Secretaria de Economia e Planejamento. Coordenadoria de Planejamento Regional. Instituto Geográfico e Cartográfico. Quadro do desmembramento territorial-administrativo dos municípios paulistas. São Paulo: IGC, 1995 
interna e externa, numa relação de indivíduos historicamente condicionados.

O processo de urbanização empregado por São Paulo demonstra um raciocínio inteligente das autoridades civis e eclesiásticas paulistas na questão de domínio do território. Com o decorrer do tempo, novos núcleos urbanos foram surgindo, ocasionando novos desmembramentos territoriais, complicando ainda mais as investidas de Minas Gerais. Tal situação, contudo, não significou o fim dos problemas, apenas os deslocou de lugar, ou seja, as disputas, até 1935, passaram a se concentrar nas áreas limítrofes. À margem dessa conjuntura, identificamos a sutileza dos paulistas em fazer dos entrantes mineiros os atores sociais que ajudaram a construir o território do nordeste paulista.

Conclui-se que, na construção do território do nordeste paulista, os indivíduos são e estão em relação com outros indivíduos mediante um processo correlato em que articulações e conflitos circunscrevem e espacializam uma unidade. Neste caso, essa unidade se deu pela presença de uma população mineira, embora governada por paulistas.

\section{Referências}

BACELLAR, C. de A. P.; BRIOSCHI, L. R. (Org.). $\mathrm{Na}$ Estrada do Anhanguera: uma visão regional da história paulista. São Paulo: Humanitas FFLCH/USP, 1999.

BELLOTTO, H. L. Autoridade e conflito no Brasil colonial: o governo do Morgado de Mateus em São Paulo: 1765-1775. São Paulo: Conselho Estadual de Artes e Ciências Humanas, 1979.

BRIOSCHI, L. R. Criando história: paulistas e mineiros no nordeste de São Paulo (1725-1835). 1995. 266 f. Tese (Doutorado em Sociologia) Faculdade de Filosofia, Letras e Ciências Humanas da Universidade de São Paulo, São Paulo, 1995.

BUENO, B. P. S. Dilatação dos confins: caminhos, vilas e cidades na formação da Capitania de São Paulo (1532-1822). Anais do Museu Paulista: História e Cultura Material, v. 17, n. 2, p. 251-294, jul.-dez. 2009.

CHIACHIRI FILHO, J. Do Sertão do Rio Pardo à Vila Franca do Imperador. Ribeirão Preto: Ribeirão Gráfica e Editora, 1986.

CINTRA, A. A questão de limites entre São Paulo e Minas. São Paulo: Typografia Paulista, 1935.
DERNTL, M. F. Método e Arte: urbanização e formação territorial na Capitania de São Paulo, 1765-1811. São Paulo: Alameda, 2013.

DOCUMENTOS INTERESSANTES para a história e costumes de S. Paulo. v. XI. Divisas de S. Paulo e Minas Gerais. São Paulo: Typografia, 1896. Disponível em: <http://www.delphos.biblioteca.unesp.br/bd/bfr/or/10.5016_10-ORD CISP-06-11_volume_11/>. Acesso em: 29 out. 2013.

FONSECA, C. D. Arraiais e vilas d'el rei: espaço e poder nas Minas setecentistas. Belo Horizonte: Editora UFMG, 2011.

MORAES, A. C. R. Território e História no Brasil. São Paulo: Annablume, 2005.

MORAES, A. C. R. Território na geografia de Milton Santos. São Paulo: Annablume, 2013.

PICCINATO JR., D. Terra urbana, patrimônio fundiário: uma análise histórica da apropriação do solo na configuração do urbano no nordeste paulista (1800-1930). 2012. 341 f. Dissertação (Mestrado em Urbanismo) - Programa de PósGraduação em Arquitetura e Urbanismo, Pontifícia Universidade Católica de Campinas, 2012.

SÃO PAULO (Estado). Secretaria de Economia e Planejamento. Coordenadoria de Planejamento Regional. Instituto Geográfico e Cartográfico. Quadro do desmembramento territorial-administrativo dos municípios paulistas. São Paulo: IGC, 1995.

SAQUET, M. A. Abordagens e concepções sobre território. 3. ed. São Paulo: Outras Expressões, 2013. 